\title{
N-Butyl-2-Cyanoacrylate Glue versus Suture for Mesh Fixation in Open Inguinal Hernioplasty
}

\author{
Arvind Shukla ${ }^{1}$, Raj Kumar Mathur², Zafar Sheikh³, Vartika Jain ${ }^{4}$
}

${ }^{1}$ Department of General Surgery, MGM Medical College, Indore, Madhya Pradesh, India. ${ }^{2}$ Department of General Surgery, MGM Medical College, Indore, Madhya Pradesh, India. ${ }^{3}$ Department of General Surgery, MGM Medical College, Indore, Madhya Pradesh, India. ${ }^{4}$ Department of General Surgery, MGM Medical College, Indore, Madhya Pradesh, India.

\section{ABSTRACT}

\section{BACKGROUND}

One of the most common surgical issues presenting to the surgical clinics is inguinal hernia. Pain after inguinal hernia surgery is debilitating and hampers the quality of life in many patients. This has been found to be due to the trauma caused by fixation of mesh with sutures. This study compares the traumatic (sutures) and nontraumatic (glue) methods of mesh fixation in inguinal hernioplasty. We wanted to compare suture and N-butyl-2-cyanoacrylate glue in fixation of mesh in open inguinal hernia repair in terms of immediate \& chronic post-operative pain, intraoperative time, recurrence, length of hospital stay \& complications, if any.

\section{METHODS}

This study was done in the department of General Surgery after Institutional Scientific \& Ethical Committee clearance. It is a prospective study conducted on 120 patients with two groups of 60 each for suture and glue (N-butyl-2-cyanoacrylate) fixation of mesh. Pain in Numerical Rating Scale, operative time and any complications were recorded with follow up at 1 week, 1 month, 3 months and 6 months.

\section{RESULTS}

It was observed that glue takes significantly lower time than suture for fixation of mesh, thereby reducing the intraoperative time significantly. Using glue reduced the mean fixation time for mesh from 10 minutes in conventional suture method to 1.7 minutes. There was also significant reduction in immediate and chronic postoperative pain in the glue group. The length of hospital stay was found to be comparable in both the groups. No post-operative complications or recurrence were recorded in either group.

\section{CONCLUSIONS}

This study confirms the effectiveness and superiority of glue over suture for mesh fixation in open inguinal hernia repair in terms of reduced immediate and chronic post-operative pain and operative time.

\section{KEY WORDS}

Inguinal Hernia, Inguinal Hernioplasty, N-Butyl-2-Cyanoacrylate Glue, PostOperative Pain, Suture, Mesh Fixation
Corresponding Author:

Dr. Zafar Sheikh,

G1 G2, Kasturi Apartments,

12 Shankar Nagar, Saket Extention,

Indore-452018, Madhya Pradesh, India.

E-mail: zafar18@gmail.com

DOI: $10.14260 / \mathrm{jemds} / 2019 / 772$

Financial or Other Competing Interests: None.

How to Cite This Article:

Shukla A, Mathur RK, Sheikh Z, et al. Nbutyl-2-cyanoacrylate glue versus suture for mesh fixation in open inguinal hernioplasty. J. Evolution Med. Dent. Sci. 2019;8(48):3575-3578, $10.14260 /$ jemds/2019/772

Submission 26-09-2019, Peer Review 11-11-2019,

Acceptance 18-11-2019,

Published 02-12-2019. 


\section{BACKGROUND}

A hernia is an abnormal protrusion of whole or part of a viscus through normal or abnormal opening in the walls of its containing cavity.[1] Hernias are one of the most common problems seen in the surgical clinics, inguinal hernias being the commonest of all, comprising $75 \%$ of all abdominal hernias. The lifetime risk of inguinal hernia is $27 \%$ in males and 3\% in females.[2] Inguinal hernioplasty is one of the most common surgical procedures, and hence improvements in clinical outcome are important. Lichtenstein hernioplasty was first recorded in 1984[3]. It is widely accepted for inguinal hernia repair due to its safety, efficacy and low rates of recurrence. ${ }^{[4]}$ Despite the success of such a technique in inguinal hernia repair, postoperative long-standing groin pain occurrence has posed a great challenge to surgeons [4]. The recorded incidence of chronic groin pain (CGP) ranged from 0.7 to $62.9 \% .^{[5,6]}$

The cause of CGP can be either neuropathic or nonneuropathic in origin. Neuropathic causes include trauma to the regional nerves of the inguinal region or nerve entrapment due to mesh-related fibrosis, postoperative fibrosis or suture fixation. Non-neuropathic causes of CGP include the periosteal reaction of sutures at the pubic tubercle, mesh displacement and inflammatory reaction to mesh. ${ }^{[7]}$ Various techniques have been used to reduce CGP. Careful dissection by identification and preservation of the regional nerves during the operation have been found to reduce the occurrence of CGP. [8]

Mesh fixation in inguinal hernia repair has traditionally been done by sutures. However recently, the technique of non-traumatic fixation of mesh using $\mathrm{N}$-butyl-2-cyanoacrylate glue (NBCA) has gained popularity in the general surgery field. Tissue glues have been found for over 20 years and used in surgery in various indications like skin wound closure,[9] haemostasis during liver surgeries,[10] and endoscopic treatment of gastroesophageal variceal bleeding.[11] Mesh fixation with glue may decrease the whole operating time and reduce the frequency of post-operative pain when compared with mesh fixation by suture.[12] NBCA glue polymerises rapidly in presence of ionic substances such as moisture, blood or tissue fluids. The polymerised form has excellent tensile strength and even has bacteriostatic property.

We wanted to compare suture and N-butyl-2cyanoacrylate glue in fixation of mesh in open inguinal hernia repair in terms of immediate \& chronic post-operative pain, intraoperative time, recurrence, length of hospital stay \& complications, if any.

\section{METHODS}

A prospective comparative study was conducted with two groups, one for the suture fixation method and the other for glue fixation method. The period of study was from August 2017 to August 2018. The patients were included in the study after explaining the study to them in detail in their local language. The patients meeting the inclusion criteria and giving the consent were included.

The study was conducted after obtaining Institutional Scientific and Ethical committee approval. A total of 120 patients were included (Keeping in mind the prevalence of the disease) and divided randomly (Alternatively) into two groups of 60 each. One group underwent suture mesh fixation and the other group underwent glue mesh fixation.

All patients of inguinal hernia posted for elective surgery who gave written informed consent were included in the study. Patients of strangulated or infected inguinal hernia, recurrent inguinal hernia and patients not willing for follow up were excluded from the study.

Lichtenstein's inguinal hernioplasty was done in all the patients. Prolene lightweight mesh was used. 'Mesh Fixation with suture' group: Prolene 2-0 suture was used in interrupted manner at multiple points to anchor the mesh medially to pubic tubercle, below to inguinal ligament and above to conjoined tendon or the internal oblique aponeurosis. Lateral to the spermatic cord, the two tails of the mesh created to accommodate the spermatic cord were fixed together with Prolene suture.

\section{'Mesh Fixation with Cyanoacrylate Glue' Group}

The mesh was fixed in the similar manner by $1 \mathrm{ml}$ of N-butyl2-cyanoacrylate glue in a syringe. The glue was applied as drops at multiple interrupted points at conjoined tendon or internal oblique aponeurosis, inguinal ligament and pubic tubercle. Lateral to the spermatic cord, the two tails of the mesh created to accommodate the spermatic cord were also fixed together with glue. Pain was monitored using the Numerical Rating Scale (NRS). Monitoring of pain was done during the hospital stay and was followed up in clinics at 1 week, 1 month, 3 months and 6 months. Patients were followed up at regular intervals for other post-operative complications and recurrence for 6 months. Parameters like intraoperative time for mesh fixation in minutes, presence of wound infection, seroma collection and allergic reactions were made note of.

All patients were subjected to a basic blood work up consisting of, complete blood count, coagulation profile, blood urea, serum creatinine, random blood glucose levels and serum electrolytes. Chest X-ray and pulmonology assessment was also done in case of any respiratory symptoms. To rule out Benign Prostatic Hyperplasia (BPH) as a predisposing factor in patients with any urinary complaints, an ultrasound of abdomen was done to assess prostate volume and the postvoid residual volume and urologist clearance was obtained before operating on the patients with BPH. All the patients were subjected to pre-anaesthetic checkup. All the cases were performed under regional block.

The patients were given basic analgesics according to NRS score for pain and were discharged accordingly. During the hospital stay, pain, allergic reactions, seroma, haematoma, wound infection and any other complaints were recorded.

SPSS software was used for analyzing the data and the mean values of the two groups were compared using "Student T test" for two sample mean. 
RESULTS

A total of 120 patients were included in the study, out of which $60(n=60)$ underwent fixation of mesh using N-Butyl2-Cyanoacrylate glue and $60(n=60)$ patients were operated with the classical Lichtenstein's hernioplasty using suture. The mean age of patients in years in the suture group was $47.90 \pm 11.5$ and that in the cyanoacrylate glue group was 45.95 \pm 9.39 . On comparison, the difference was found to be statistically insignificant with $P$ value $>0.05$. [Table 1$]$

\begin{tabular}{|c|c|c|c|c|}
\hline Material Used & $\mathbf{N}$ & Mean Age (Years) & S.D. & p \\
\hline N-butyl-2-cyanoacrylate & 60 & 47.90 & 11.5 & 0.319 \\
\cline { 1 - 4 } Suture & 60 & 45.95 & 9.39 & Non-Significant \\
\hline Table 1. Comparison of Mean Age in the Two Groups \\
\hline
\end{tabular}

\begin{tabular}{|l|c|c|c|c|c|}
\hline Parameter & Group & N & Mean time (In Minutes) & S.D. & p \\
\hline \multirow{2}{*}{ Mesh Fixation } & $\begin{array}{c}\text { N-butyl-2- } \\
\text { cyanoacrylate glue }\end{array}$ & 60 & 1.73 & 0.602 & \multirow{2}{*}{$0.000^{*}$} \\
\cline { 2 - 6 } & Suture & 60 & 10.10 & 0.579 & \\
\hline \multicolumn{6}{|l|}{ Table 2. Comparison of Mean Mesh Fixation Time } \\
\hline
\end{tabular}

\begin{tabular}{|c|c|c|c|c|c|}
\hline Pain & Group & $\mathbf{N}$ & Mean & S.D. & p \\
\hline \multirow{2}{*}{1 Week } & $\mathrm{N}$-butyl-2-cyanoacrylate glue & 60 & 2.88 & 1.22 & \multirow{2}{*}{$0.000^{*}$} \\
\hline & Suture & 60 & 5.20 & 0.953 & \\
\hline \multirow{2}{*}{1 Month } & N-butyl-2-cyanoacrylate glue & 60 & 0.317 & 0.725 & \multirow{2}{*}{$0.000^{*}$} \\
\hline & Suture & 60 & 2.47 & 1.05 & \\
\hline \multirow{2}{*}{3 Month } & N-butyl-2-cyanoacrylate glue & 60 & 0.00 & 0.000 & \multirow{2}{*}{$0.000^{*}$} \\
\hline & Suture & 60 & 1.10 & 0.933 & \\
\hline \multirow{2}{*}{6 Month } & $\mathrm{N}$-butyl-2-cyanoacrylate glue & 60 & 0.00 & 0.000 & \multirow{2}{*}{$0.000^{*}$} \\
\hline & Suture & 60 & 0.75 & 0.704 & \\
\hline \multicolumn{6}{|c|}{ Table 3. Comparison of Mean Pain Score at Different Durations } \\
\hline $\mathrm{p}<0.05$ & cant $(*)$ & & & & \\
\hline
\end{tabular}

Time taken for fixation of mesh measured in minutes, was on an average of $1.73 \pm 0.602$ minutes with cyanoacrylate glue while that with suture took an average of $10.10 \pm 0.579$ minutes. This difference was statistically significant with $\mathrm{P}$ value $<0.05$. Hence it is significant that mesh fixation with glue was quicker and easier [Table 2]. Immediate postoperative pain within first week of surgery was evaluated based on Numerical Rating Scale with a mean NRS score of $2.88 \pm 1.22$ and $5.20 \pm 0.953$ in glue and suture fixation respectively with a significant difference with a $\mathrm{p}$ value of $<0.05$ A clinical check-up was performed at one, three and six months. Chronic groin pain was considered significant if it was still present at the surgical site for a period of more than three months after the operation.

The mean NRS score for glue fixation at three months was 0 and that for suture fixation was $1.10 \pm 0.933$. The mean NRS score for glue fixation at six months was 0 and for suture fixation was $0.750 \pm 0.704$. This difference in pain at three and six months between the two groups was found to be significant with the $\mathrm{P}$ value of $<0.05$. [Table 3] There was no significant difference between the two groups in terms of length of hospital stay. No recurrence of inguinal hernia or postoperative complications like allergic reactions, haematoma or seroma collection or wound infection was encountered in either of the two groups.

\section{DISCUSSION}

Lichtenstein's tension free hernia repair is the most commonly practiced hernia surgery due to its superiority over the other open techniques in several ways. However, chronic groin pain is a very common postoperative complaint by the patients which depends on various factors like the type of mesh used, method of mesh fixation and also the subjective threshold of pain.[13] Chronic groin pain has been defined as the pain in the groin region post hernioplasty lasting beyond a period of 3 months.[14] Why it is important to address this issue is that a long-lasting pain can significantly alter the quality of life of the individuals. One of the several factors responsible for chronic groin pain post hernioplasty is the type of mesh fixation. Trauma to the tissues with suture causes inflammatory reaction at the suture points.

According to a study by Losi P et al, the use of glue shows a reduced inflammatory response at the site.[15] Goeda et al conducted a meta-analysis which showed that surgery using glue is significantly faster as opposed to suture. The immediate and chronic pain is also lower in the glue group. ${ }^{[16]}$ Our results were compatible to a study by Tebala et al which was carried out on 45 male patients (26 of them used cyanoacrylate glue fixation of the mesh) with no recurrence.[17] Their study concluded that the pain from 48 hours to one month (Immediate post-operative pain) after surgery is lower in the glue group when compared to suture. However, there was no significant difference in chronic pain between the two methods in their study. Negro P et al found that the suture group experienced a higher pain in the immediate postoperative period as compared to the tissue glue group.[18] Matikainen et al concluded in their study that the immediate post- operative pain is significantly less with glue. However, there was no difference in the chronic pain experienced by both the groups.[19] Quyn et al found a significantly lower acute and chronic pain with the use of glue. ${ }^{[20]} \mathrm{A}$ lower immediate and chronic post- operative pain with the use of glue was also concluded in the study by Sun P et al.[21] The usage of glue in mesh fixation has significantly proved its efficacy with regard to decreasing the time needed for mesh fixation in open inguinal hernia repair, as the mean time taken for mesh fixation with glue was 1.73 minutes in our study. Helmy reported a significant decrease in the operative time using Glue mesh fixation for unilateral inguinal hernia repair where $51.2 \%(22 / 43)$ of cases were handled in less than 30 min. [22] Lin $\mathrm{H}$ et al found a significantly lower immediate and chronic pain after using glue in the surgery for inguinal hernia. The operative time was also significantly lowered with the use of glue. ${ }^{[23]}$ In our study, it is found that the operative time is reduced with glue as compared to the suture fixation method which is consistent with many other studies. Pain in the immediate post-operative period, up to one week is also significantly lower in the glue group. Pain at different time intervals in the post-operative period has all been found to be significantly lower in the glue group. A significantly higher chronic groin pain was observed with suture mesh fixation as compared to glue. Complications like seroma, hematoma, allergic reactions or wound infection have not been encountered in this study in either of the groups.

\section{CONCLUSIONS}

From our study, it can be concluded that fixation of mesh with N-butyl-2-cyanoacrylate glue is superior to that with 
sutures in several aspects. The immediate postoperative and chronic postoperative pain is considerably reduced with glue without any intraoperative or postoperative complications. The use of glue also reduces the operative time which can be very productive in high volume centres. Hence, glue can be justified as a good replacement for suture in inguinal hernia repair, providing a better quality of life with lesser postoperative co-morbidities.

\section{REFERENCES}

[1] Malangoni MA, Rosen MJ. Hernias. Sabiston textbook of Surgery. 19th edn. Saunders Publication 2012: p. 1114-5.

[2] Brunicardi F, Andersen D, Billiar T, et al. Schwartz's principles of surgery. $10^{\text {th }}$ edn. McGraw-Hill Education/Medical 2014: p. 1495-591.

[3] Amid PK. Lichtenstein tension-free hernioplasty: its inception, evolution and principles. Hernia 2004;8(1):17.

[4] Kurzer M, Belsham PA, Kark AE. The Lichtenstein repair for groin hernias. Surg Clin N Am 2003;83(5):1099-117.

[5] Kingsnorth AN, Bowley DM, Porter C. A prospective study of 1000 hernias: results of the Plymouth Hernia Service. Ann R Coll Surg Engl 2003;85(1):18-22.

[6] Cunningham J, Temple WJ, Mitchell P, et al. Cooperative hernia study. Pain in the postrepair patient. Ann Surg 1996;224(5):598-602.

[7] Sajid MS, Leaver C, Baig MK, et al. Systematic review and meta-analysis of the use of lightweight versus heavyweight mesh in open inguinal hernia repair. Br J Surg 2012;99(1):29-37.

[8] Alfieri S, Rotondi F, Di Giorgio A, et al. Influence of preservation versus division of ilioinguinal, iliohypogastric and genital nerves during open mesh herniorrhaphy: prospective multicentric study of chronic pain. Ann Surg 2006;243(4):553-8.

[9] Keng TM, Bucknall TE. A clinical trial of tissue adhesive (histoacryl) in skin closure of groin wounds. Med J Malaysia 1989;44(2):122-8.

[10] Chapman WC, Clavien P, Fung JJ, et al. Managing hepatic bleeding with autologous plasma/collagen-based fibrin sealant. Arch Surg 2001;136(8):967.

[11] Dhiman RK, Chawla Y, Taneja S, et al. Endoscopic sclerotherapy of gastric variceal bleeding with N-butyl2- cyanoacrylate. J Clin Gastroenterol 2002;35(3):222-7.
[12] Canonico S, Santoriello A, Campitiello F, et al. Mesh fixation with human fibrin glue (Tissucol) in open tension-free inguinal hernia repair: a preliminary report. Hernia 2005;9(4):330-3.

[13] Demetrashvili Z, Metreveli T, Vibliani K, et al. Chronic pain following Lichtenstein inguinal hernia repair: a single surgeon's experience. Open Access J Surg 2016;1(2):555557.

[14] Hakeem A, Shanmugam V. Inguinodynia following Lichtenstein tension-free hernia repair: a review. World J Gastroenterol 2011;17(14):1791-6.

[15] Colvin HS, Rao A, Cavali M, et al. Glue versus suture fixation of mesh during open repair of inguinal hernias: a systematic review and meta-analysis. World J Surg 2013;37(10):2282-92.

[16] De Goede B, Klitsie PJ, Van Kempen BJ, et al. Metaanalysis of glue versus sutured mesh fixation for Lichtenstein inguinal hernia repair. $\mathrm{Br} \mathrm{J}$ Surg 2013;100(6):735-42.

[17] Tebala GD, Tognoni V, Tristram Z, et al. Cyanoacrylate glue versus suture fixation of mesh in inguinal hernia open repair: a randomized controlled clinical trial. Gastroenterol \& Hepatol: Open Access 2015;2(5):00054.

[18] Negro P, Basile F, Brescia A, et al. Open tension-free Lichtenstein repair of inguinal hernia: use of fibrin glue versus sutures for mesh fixation. Hernia 2011;15(1):714.

[19] Matikainen M, Kössi J, Silvasti S, et al. Randomized clinical trial comparing cyanoacrylate glue versus suture fixation in Lichtenstein hernia repair: 7-year outcome analysis. World J Surg 2017;41(1):108-13.

[20] Quyn AJ, Weatherhead KM, Daniel T. Chronic pain after open inguinal hernia surgery: suture fixation versus selfadhesive mesh repair. Langenbeck's Arch Surg 2012;397(8):1215-8.

[21] Sun P, Cheng X, Deng S, et al. Mesh fixation with glue versus suture for chronic pain and recurrence in Lichtenstein inguinal hernioplasty. Cochrane Database Syst Rev 2017;2:CD010814.

[22] Helmy AHI. Lichtenstein repair of inguinal hernia: new modalities for mesh fixation; the use of tissue adhesive glue (Histoacryle: $N$ Butyl 2 cynoacrylate) to fix the mesh. Egypt J Surg 2000;19:276-83.

[23] Lin H, Zhuang Z, Ma T, et al. A meta-analysis of randomized control trials assessing mesh fixation with glue versus suture in Lichtenstein inguinal hernia repair. Medicine (Baltimore) 2018;97(14):e0227. 